Article

\title{
Construction of a New Type of Coal Moisture Control Device Based on the Characteristic of Indirect Drying Process of Coking Coal
}

\author{
Ming Yan, Xinnan Song, Jin Tian, Xuebin Lv, Ze Zhang, Xiaoyan Yu and Shuting Zhang * \\ School of Environmental Science and Engineering, Tianjin University, Tianjin 300354, China; \\ 13120685218@163.com (M.Y.); simple523929@sina.com (X.S.); nijnait_tj@163.com (J.T.); xbltju@tju.edu.cn (X.L.); \\ 15097555728@163.com (Z.Z.); yxy198208@163.com (X.Y.) \\ * Correspondence: zhangst@tju.edu.cn
}

Received: 17 July 2020; Accepted: 7 August 2020; Published: 12 August 2020

check for updates

\begin{abstract}
This paper presents an in-depth study on the indirect drying characteristics and interface renewal. By comparing the drying rate curve, it is found that shortening the surface drying stage, which contains a repeated evaporation-diffusion-condensation process of moisture, is the key to improve the total drying efficiency. By stirring the coal and realizing the interface renewal between the bottom layer and the surface layer, the drying efficiency reached seven times than that of static indirect drying. Based on indirect heat transfer with high heat and mass transfer rate, a new type of indirect heat transfer moving bed coal moisture control device is designed. At the same time, Fluent fluid mechanics software is used for mathematical modeling and simulation experiments. It is proved that the designed moving bed coal moisture control device has a good application prospect in coal pre-drying technology.
\end{abstract}

Keywords: moisture; coal pre-drying; heat; mass; drying kinetics

\section{Introduction}

Research data from 2017 "BP World Energy Outlook" showed that coal still accounted for a massive $30 \%$ of the world's primary energy structure, second only to oil which accounted for about $32 \%$. China is the biggest producer, as well as consumer of coke, which is produced from coking coal [1].

The iron and steel industry is a pillar in the Chinese economy. It provides basic raw materials for national economic and industrial construction, but it also consumes a large amount of coal [2]. In 2016, the Chinese iron and steel industry consumed 618 million tons of coal, accounting for $16 \%$ of the total coal consumption. Metallurgical coke consumed in the iron and steel industry needs to be obtained through high-temperature carbonization with high-quality coke blending [3]. However, the high moisture content of coking coal (9-12\%) leads to high energy consumption and low efficiency of the coking plant. Therefore, setting a pre-drying process before coking could efficiently lower the energy consumption, improve the quality of the coke, increase the blending ratio of non- or weak-caking coal, reduce the production of greenhouse gases and harmful gases, as well as reduce the impact on the water environment [4-7].

Several pre-drying technologies have been developed for coking coal dehydration, including coal moisture control (CMC), which has been concerned increasingly. Many scholars have made great progress in the field of CMC. Kato et al. proved that with the coal moisture being reduced to 5-6\% with $\mathrm{CMC}$, the advantages of less heat consumption for carbonization, higher productivity and better coke quality were gained $[8,9]$. Liu et al. proposed a new coal classifying moisture control (CCMC) process was to implement simultaneously the classification for 0-3.0 $\mathrm{mm}$ particles and coal moisture control (CMC) [10]. 
Coal Moisture Control is a pretreatment technology aimed at saving energy and reducing consumption. The water content of coking coal is reduced to around $6 \%$ through the CMC unit $[9,10]$.

A comprehensive analysis of the technical parameters of equipment and production efficiency of several CMC technologies is summarized in Table 1.

Table 1. Comparison of technical parameters of several CMC technologies.

\begin{tabular}{|c|c|c|c|c|c|}
\hline \multicolumn{2}{|c|}{ CMC Technology } & \multirow{2}{*}{$\begin{array}{c}\text { Heat Carrier } \\
\text { Heat Transfer Oil }\end{array}$} & \multirow{2}{*}{$\begin{array}{c}\begin{array}{c}\text { Heat Carrier } \\
\text { Temperature } /{ }^{\circ} \mathrm{C}\end{array} \\
195\end{array}$} & \multirow{2}{*}{$\begin{array}{c}\text { Energy Saving Effect of } \\
\text { Producing } 1 \text { Tons of Dry Coal } \\
\text { /kgce } \cdot \mathrm{t}^{-1}\end{array}$} & \multirow{2}{*}{$\begin{array}{c}\text { Processing } \\
\text { Capacity } \\
/ \mathrm{t} \cdot \mathrm{h}^{-1} \\
\end{array}$} \\
\hline \multirow{3}{*}{$\begin{array}{l}\text { Rotary } \\
\text { CMC } \\
\text { (Indirect) }\end{array}$} & $\begin{array}{c}\text { First } \\
\text { Generation }\end{array}$ & & & & \\
\hline & \multirow{2}{*}{$\begin{array}{l}\text { Second } \\
\text { Generation }\end{array}$} & Hot Flue Gas & 350 & \multirow{2}{*}{$\begin{array}{c}1.07 \\
\text { Wet content decreased by } 2.5 \%\end{array}$} & \multirow[b]{2}{*}{$330-400$} \\
\hline & & Superheated Steam & $150-180$ & & \\
\hline \multirow{2}{*}{\multicolumn{2}{|c|}{$\begin{array}{l}\text { Fluidized-bed CMC } \\
\text { (Direct) } \\
\text { Third Generation }\end{array}$}} & \multirow{2}{*}{$\begin{array}{l}\text { Superheated Steam, } \\
\text { Hot Air, High } \\
\text { Temperature Flue Gas }\end{array}$} & \multirow{2}{*}{$180-230$} & $\begin{array}{c}0.73 \\
\text { Wet content decreased by } 2.5 \%\end{array}$ & \multirow{2}{*}{$125-300$} \\
\hline & & & & $\begin{array}{c}4.05 \\
\text { Wet content decreased by } 4.2 \%\end{array}$ & \\
\hline
\end{tabular}

kgce $\mathrm{t}-1 \mathrm{~kg}$ standard coal consumed in producing $1 \mathrm{t}$ production.

The dryers used in the CMC technology mainly include fluidized bed and rotary drum, which represent direct coal drying technology and indirect coal drying technology, respectively. After a comprehensive analysis of the performance parameters of the fluidized bed and rotary drum, it is found that direct drying has the advantage of high drying efficiency, due to the direct contact and large contact area between coal and heat source-but it has a severe problem, which is large particulate matter emission. The fine particles in the carbonization gas could block the system [11], as well as cause a health problem of workers [12]. It can be seen from Table 1 that considering the required heat carrier temperature and processing capacity, the indirect heat transfer rotary drying method is advantageous. In addition, in the control of dust pollution, indirect heat transfer has obvious advantages over direct heat transfer. There is no need for a large and complicated dust removal device. The heat carrier is isolated from the coal material body, which greatly reduces the risk of ignition, and the operation is more stable and safer. However, low mass and heat transfer efficiency has always been the most critical factor restricting the commissioning and use of indirect drying, so enhancing the heat and mass transfer efficiency of indirect drying devices has become a breakthrough in the design of new coal moisture control devices.

Except for fluidized bed and rotary drum, there are other kinds of dryer that are commonly used, such as moving bed, which is widely used especially in agricultural filed. For example, abundant literature has been made on research of moving bed used in the drying of soybeans, seeds, grain, etc. [13-16]. However, the application of moving bed dryer in the coal drying is barely studied. Zhang. et al. developed a numerical model for the lignite drying process in the packed moving bed and proved the dryer's efficiency in lignite drying [13]. The moving bed dryer has the following merits, such as simple structure, low investment requirement, low energy consumption [17]. Therefore, designing an indirect moving bed dryer which relies on coal's own gravity in the material movement will be a major direction for improving the current indirect CMC technology.

In this article, the characteristics of indirect drying and the law of water migration, as well as the influence of factors, such as material thickness, heat source temperature and interface renewal on the efficiency of indirect drying are studied. Based on the basic parameters of indirect drying characteristics which have been studied, and combined with actual engineering requirements, a new type of coal moisture control device which should be categorized as moving bed dryer was designed. The simulation software-Fluent (ver. 15.0, ANSYS, USA)was used to analyze the heat transfer and coal movement in the newly designed device. The results of this study provide a reference for the application of the new moving bed coal moisture control device in coal pre-drying technology. 


\section{Materials and Methods}

\subsection{Coal Sample}

The coking coal used in this study is from Xingtai City, Hebei Province, China, and it was obtained after the coal blending process. Liu et al. found that the fraction below $3.0 \mathrm{~mm}$ was dominant in the formation of the moisture of the raw coal for coking [10]. Thus, the particle size of coal used in the following experiments is below $3.0 \mathrm{~mm}$, and the initial moisture content is $12 \%$. The ultimate and proximate analysis figures of the coal are presented in Table 2.

Table 2. Ultimate and proximate analysis of coal samples used in the experiment.

\begin{tabular}{cccccc}
\hline \multicolumn{2}{c}{ Proximate Analysis (wt\%, d) } & \multicolumn{4}{c}{ Ultimate Analysis (wt \%, daf) } \\
\hline $\mathrm{A}_{\mathrm{d}}$ & $\mathrm{V}_{\mathrm{daf}}$ & $\mathrm{S}$ & $\mathrm{C}$ & $\mathrm{H}$ & $\mathrm{N}$ \\
\hline 7.84 & 36.22 & 0.37 & 86.32 & 5.51 & 1.51 \\
\hline
\end{tabular}

daf: dry and ash-free base; d: dry base; $A_{d}$ : ash (dry base).

\subsection{Design of a New Type of Indirect Coal Drying Device}

Based on the indirect drying, which causes less pollution, a new device is designed that is aiming at avoiding the issue of large energy consumption caused by the large-scale agitator. The construction is shown in Figure 1.

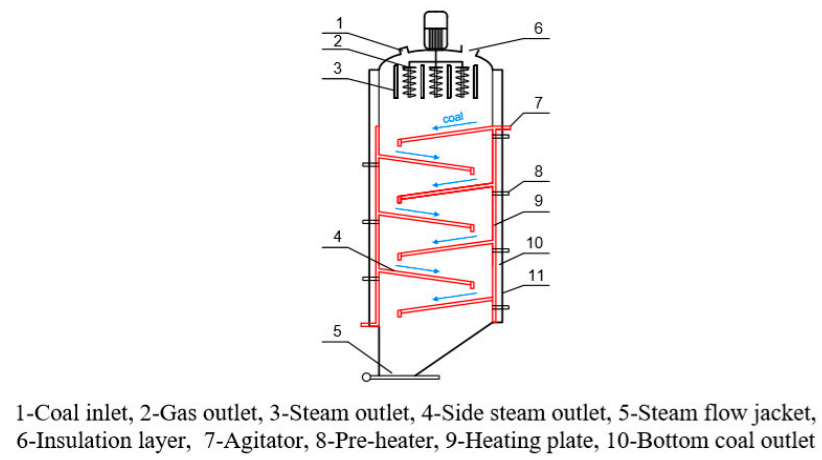

Figure 1. Structure diagram of a new type of a moving bed coal moisture control device.

The coal enters the device by the coal inlet and contacts the preheater, and its temperature rises fast by preheating, as well as agitating. It then falls onto the first inclined heating plate. Seven inclined heating plates are all hollow and use superheated steam as a heat source. The coal forms a laminar flow on the plate along the coal flow direction, and falls onto the next inclined heating plate at the descending port until it is discharged from the coal outlet. The coal deflector at the end of the inclined heating plate appropriately controls the coal to keep the same thickness when falling. Due to the good insulation of the dryer shell and the insulation layer, the water vapor does not condense, but is led out from the top steam outlet and the side steam outlet.

On the inclined plates, the heat and mass transfer directions are all upward, perpendicular to the inclined plate. When the coal is overturned at the descending port, it undergoes violent disturbance. The surface coal and the bottom coal flowing on the next inclined plate are different from that on the previous inclined plate, which is similar to agitation. However, coal moves downwards along the plates by its own gravity, greatly reducing the energy consumption of traditional indirect drying devices on agitation. 


\subsection{Static and Stirring Side Wall Indirect Drying Experiment}

In order to explore the laws of heat and mass transfer during coal drying under static and stirring conditions, the sidewall indirect drying experiment was carried out. The device is shown in Figure 2. Wet coal (wt 12\% water content) was placed in the circular tank, and a layered wire mesh circle was placed in the middle of the tank which divided the round tank into three parts by dividing the radius equally. The thickness of each layer was $2.75 \mathrm{~cm}$. Four thermocouples were inserted into the coal at the locations marked at point $\mathrm{O}, \mathrm{A}, \mathrm{B}$, and $\mathrm{C}$. The distance from the heat source to thermocouples was $1.375 \mathrm{~cm}$ at point $\mathrm{A}, 4.125 \mathrm{~cm}$ at point $\mathrm{B}, 6.875 \mathrm{~cm}$ at point $\mathrm{C}$, and $8.25 \mathrm{~cm}$ at point $\mathrm{O}$. The coal was divided into three parts: an inner layer, middle layer and outer layer. The insertion depth of the thermocouple is half the height of the coal sample depth. The round tank was placed in a thermostatic oil bath at $150{ }^{\circ} \mathrm{C}$. The temperature data was recorded by each thermocouple every $2 \mathrm{~s}$, starting from the time when the tank was placed in the oil bath. Samples were taken every $5 \mathrm{~min}$ from the three layers of the coal in the circular tank and tested for moisture, respectively. At each moment, three such samples were taken as parallel.

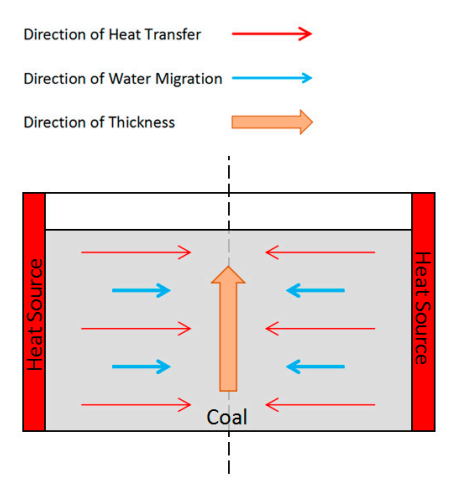

(a)

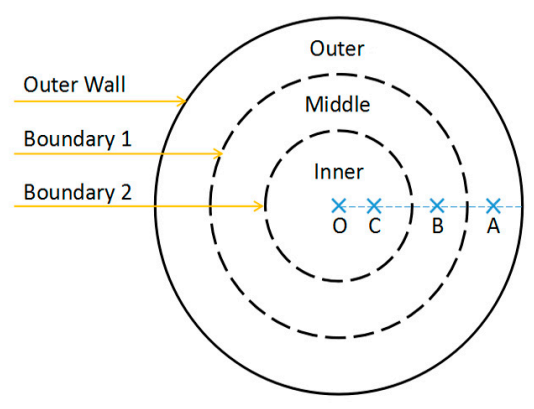

(b)

Figure 2. The sidewall drying device: (a) Heat and mass transfer direction in the device; (b) circular tank internal partition and thermocouple insertion positions.

Wet coal (water content $12 \%$ ) was then placed in the same circular tank with an agitator inserted into the coal. The gear motor of the agitator above the blade was fixed above the circular tank. At the moment of putting in the oil bath, the thermocouple data recorder and the gear motor switch were turned on at the same time, and the blades were rotated at a uniform speed of $15 \mathrm{r} / \mathrm{min}$. Every five minutes, coal from the inner, middle, outer areas of the tank were mixed, sampled and tested for moisture. The coal, at various positions, was marked, and the average angular velocity during mixing was measured.

\subsection{Indirect Thin-Layer Plane Drying Experiment}

In the sidewall heat transfer experiment, the direction of moisture migration is from the outside to the inside, which is the same as the heat transfer direction and perpendicular to the thickness direction. To analyze the influence of the coal thickness in the heat transfer direction on the law of moisture migration, an indirect thin-layer plane heat transfer experiment was designed. The indirect thin-layer plane drying experiment was designed, as shown in Figure 3. Wet coal (wt $12 \%$ water content) was placed in the acrylic cubic device, laying on a preheated electric heating plate $\left(140{ }^{\circ} \mathrm{C}, 150{ }^{\circ} \mathrm{C}\right.$ and $160^{\circ} \mathrm{C}$ ), till the thickness reached $8 \mathrm{~cm}, 4 \mathrm{~cm}$, and $2 \mathrm{~cm}$, respectively. The thermocouples were inserted into the coal in a parallel direction to the heating plate, and the insertion depth was half of the width of the device. For the coal thickness of $8 \mathrm{~cm}$, four thermocouples were installed at $2 \mathrm{~cm}, 4 \mathrm{~cm}, 6 \mathrm{~cm}$, and $8 \mathrm{~cm}$ (surface layer) from the bottom heat source, respectively. By analogy, two thermocouples were installed for the coal thickness of $4 \mathrm{~cm}, 2 \mathrm{~cm}, 4 \mathrm{~cm}$ (surface layer) from the bottom plate heat source, respectively. For the $2 \mathrm{~cm}$ thick coal, only the temperature of $2 \mathrm{~cm}$ (surface layer) from the bottom heat 
source was measured. When the thermocouple was inserted, the temperature values were recorded every $2 \mathrm{~s}$. Samples were taken from the front stratified sampling port every $5 \mathrm{~min}$. The sampling height was the same as the thermocouple insertion height. At each moment, three samples from each layer were taken as parallel.

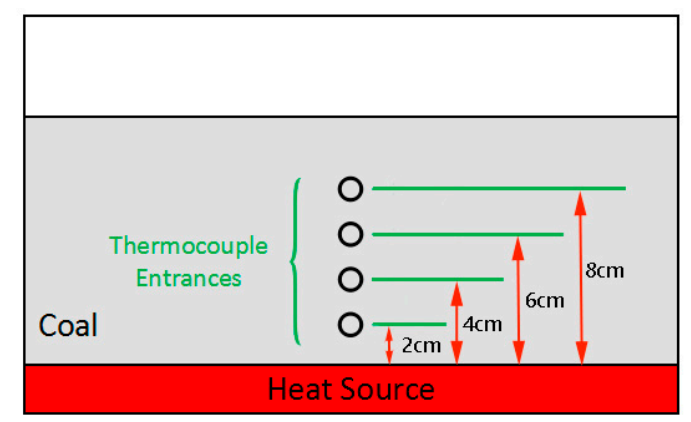

Figure 3. The indirect thin-layer plane drying device with thermocouple insertion positions.

\subsection{Simulation of Heat Transfer in a New Type of Indirect Coal Drying Device based on Fluent}

Gambit modeling steps are as follows:

1. Create a two-dimensional geometric closed figure according to the geometric parameters of the device. The closed figure is the inner cavity of the device, and the modeling ratio is 1:1;

2. The Cell Zone Conditions of the closed figure are set to fluid type, and the fluid zone is inside the closed figure;

3. Set the Boundary Conditions of all sides of the seven inclined plates to wall type;

4. Set the Boundary Conditions on the outer wall of the left and right devices to wall type;

5. Set the Boundary Conditions on the top of the device to mass-flow-inlet type; wet coal powder enters the fluid area from the top;

6. Set the Boundary Conditions at the bottom of the device to mass-flow-inlet type, and the dried coal powder flows out of the fluid area from the bottom;

7. Set the Boundary Conditions of the steam outlet under the inclined plate to pressure-outlet type; Import the grid model obtained into Fluent15.0 to set multiple flow model parameters. The setting steps are as follows:

1. Select the mixture multiphase flow model and activate the Implicit Body Force option.

2. Check Energy Equation to activate the heat balance calculation.

3. Two types of materials are defined, pulverized coal and gaseous water. Create a pulverized coal material in Material, with a density of $700 \mathrm{~kg} / \mathrm{m}^{3}$, a thermal conductivity of $0.478 \mathrm{~W} / \mathrm{m} \cdot \mathrm{K}$ (data from a previous research), and a viscosity of $1.72 \times 10^{-5} \mathrm{~kg} / \mathrm{m} \cdot \mathrm{s}$. Add gaseous water-vapor $\left(\mathrm{H}_{2} \mathrm{O}\right)$ to the material, density $0.5542 \mathrm{~kg} / \mathrm{m}^{3}$, thermal conductivity $0.0261 \mathrm{~W} / \mathrm{m} \cdot \mathrm{K}$, viscosity default value $1.34 \times 10^{-5} \mathrm{~kg} / \mathrm{m} \cdot \mathrm{s}$.

4. Define the main phase and the second phase. In define/phases, set the main phase to pulverized coal and the second phase to water-vapor $\left(\mathrm{H}_{2} \mathrm{O}\right)$, and set its diameter to $0.0002 \mathrm{~m}$.

5. Keep the calculated operating environment pressure at 1 atmosphere under the Operating Conditions option. Activate the Gravity option, set the gravity acceleration in the $\mathrm{x}$ direction to 0 , and the acceleration value in the y direction to-9.81.

6. Select mixture in the phase of Boundary Conditions, and the Pressure Outlet dialog box will pop up. Set Gauge Pressure and Backflow Total Temperature to 0 and 372, respectively. Select the second phase water-vapor $\left(\mathrm{H}_{2} \mathrm{O}\right)$ and set Backflow Volume Fraction to 0 .

7. Set the Thermal Conditions on all sides of seven inclined plates to a constant temperature, and set the Thermal Conditions on the outer wall of the left and right sides of the device to Heat Flux, with a value of $0 \mathrm{w} / \mathrm{m}^{2}$. 
8. After Solution Initialization is initialized, iterate over 2000 steps to calculate.

\section{Results and Discussion}

\subsection{Influence of Coal Layer Thickness on the Drying Process of Thin-Layer Plane}

In direct heat transfer, the drying rate is closely related to the internal diffusion rate of moisture in the particles $[18,19]$. By analogy, in indirect heat transfer, the drying rate is closely related to the internal diffusion rate in the whole drying material. To increase the rate of internal diffusion, the following methods can be taken:

1. Make the direction of thermal diffusion and wet diffusion consistent. When the direction of thermal diffusion and wet diffusion are consistent, the enhanced heat transfer can increase the temperature gradient in the material;

2. Reduce the thickness of the drying body, or change the single-sided drying to double-sided drying;

In the indirect thin-layer plane drying experiment, the direction of thermal diffusion and wet diffusion was the same from beginning to end. Coking coal with a thickness of $8 \mathrm{~cm}, 4 \mathrm{~cm}$, and $2 \mathrm{~cm}$ was selected for drying, and the temperature change of each layer in the drying time of $4500 \mathrm{~s}$ was shown in Figure 4.
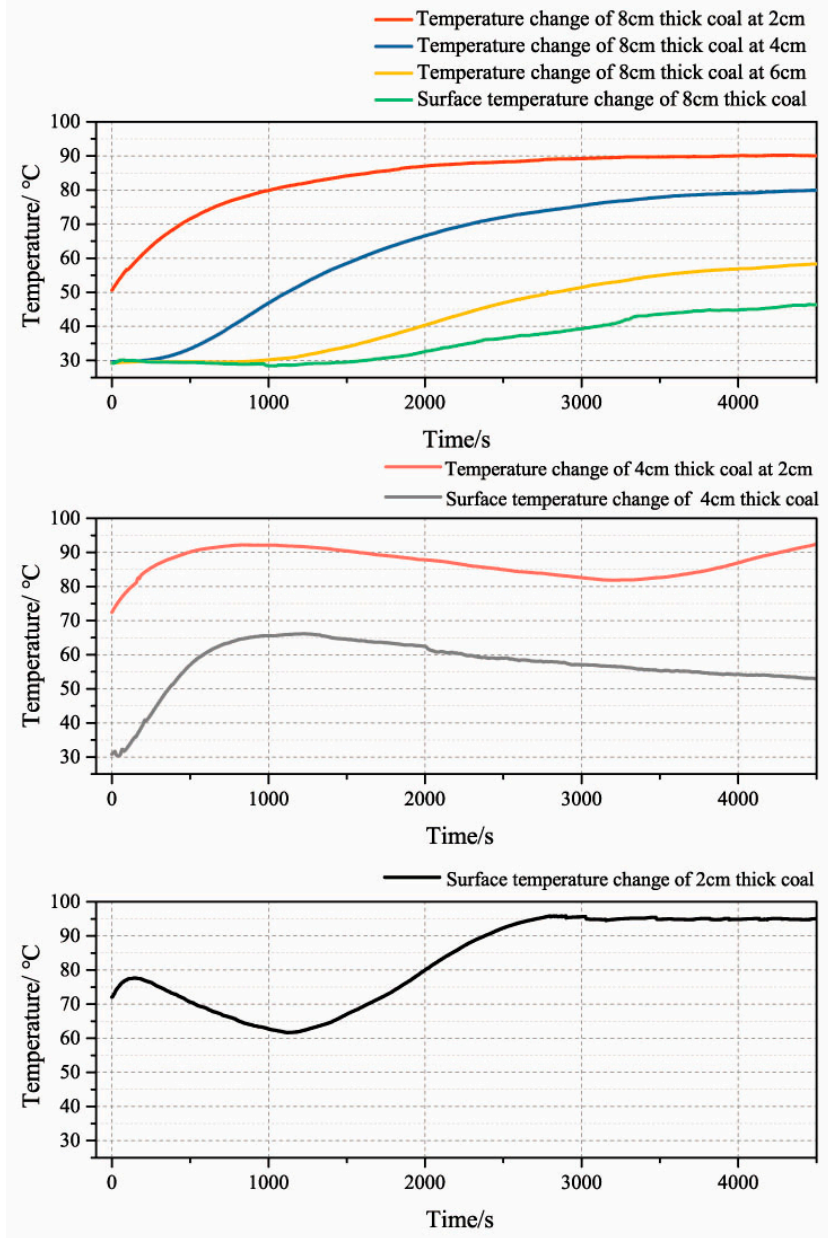

Figure 4. Temperature change of different thickness coal in thin-layer drying experiment.

In the experiment with the $8 \mathrm{~cm}$ thick coal, the temperature at $2 \mathrm{~cm}$ and $4 \mathrm{~cm}$ from the heat source showed a continuously rising trend, and the difference is that the heating rate of the coal at $2 \mathrm{~cm}$ which was closer to the heat source was faster. After being dried for $4300 \mathrm{~s}$, the temperature at $2 \mathrm{~cm}$ increased 
from $31.16{ }^{\circ} \mathrm{C}$ to $90^{\circ} \mathrm{C}$ and stabilized at $90{ }^{\circ} \mathrm{C}$. The temperature of coal at $4 \mathrm{~cm}$ rose from the initial temperature of $29.64{ }^{\circ} \mathrm{C}$ to $80.2^{\circ} \mathrm{C}$ after $4700 \mathrm{~s}$ and stabilized. The temperature of coal at $6 \mathrm{~cm}$ and $8 \mathrm{~cm}$ showed a state of small decline and then a rise. The temperature drop of the coal at $6 \mathrm{~cm}$ occurred within the time period of $470 \mathrm{~s}$ to $690 \mathrm{~s}$, of about $0.2^{\circ} \mathrm{C}$. While the temperature drop of the coal at $8 \mathrm{~cm}$ occurred within the time period of $480 \mathrm{~s}$ to $1040 \mathrm{~s}$, of about $0.6^{\circ} \mathrm{C}$. With increasing thickness of coal, moisture and heat transfer were slow along the same direction. The coal in the surface area was heated very slowly, the surface temperature $(8 \mathrm{~cm})$ only increased from $29.12{ }^{\circ} \mathrm{C}$ to $46.38^{\circ} \mathrm{C}$ after $4500 \mathrm{~s}$.

In the experiment with $4 \mathrm{~cm}$ thick coal, the temperature change was different from that of $8 \mathrm{~cm}$. The temperature of the surface layer $(4 \mathrm{~cm})$ and the inner layer $(2 \mathrm{~cm})$ was initially in an ascending stage; the peak temperature values were $92.24^{\circ} \mathrm{C}$ and $66.19^{\circ} \mathrm{C}$, respectively. The temperature of the surface layer $(4 \mathrm{~cm})$ and the inner layer $(2 \mathrm{~cm})$ started to decrease after $830 \mathrm{~s}$ and $1230 \mathrm{~s}$, which was probably due to the fact that the thickness was reduced by half so that the mass transfer resistance reduced. When the moisture vaporization in coal absorbed a large amount of heat, water vapor was easier to escape into the surface dry air. When the heat taken away by water vapor was larger than the heat added by the bottom heat source, the temperature dropped. After $3000 \mathrm{~s}$, when the surface moisture content decreased to a critical value and the heat loss taken away by water vapor was equal to the bottom heat source transfer heat transfer rate, the surface coal temperature experienced a stable stage, it was stable at about $81.86^{\circ} \mathrm{C}$. After $3500 \mathrm{~s}$, when the surface water content further decreased, the evaporation rate slowed down, and when the rate of heat loss carried away by water vapor was less than the rate of heat transferred from the bottom heat source, the surface temperature rose again.

At the thickness of $2 \mathrm{~cm}$, the variation trend of surface temperature in the first $1000 \mathrm{~s}$ was consistent with that of the thickness of $4 \mathrm{~cm}$, which increased first and then decreased, but the temperature decrease stage was much earlier, and the degree of decline was also larger.

The surface water content and temperature change data were analyzed at the same time. The results were shown in Figure 5.
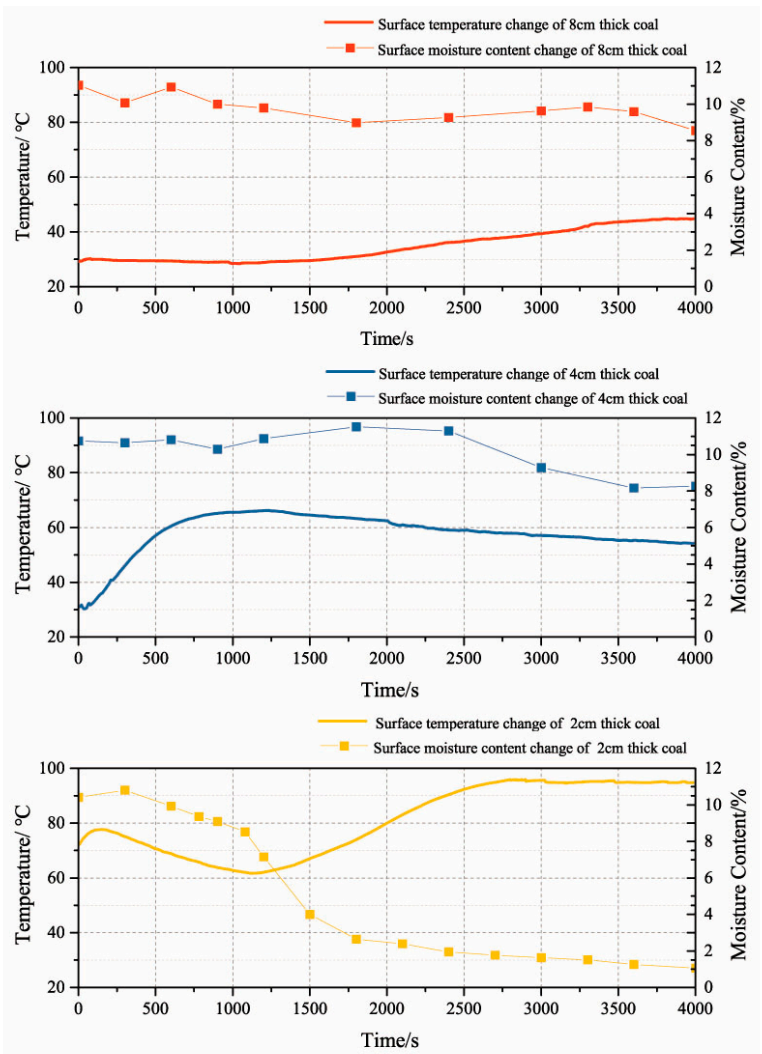

Figure 5. Surface temperature and moisture content change of different thickness coal in thin-layer drying experiment. 
At the thickness of $8 \mathrm{~cm}$, the water content of the surface layer had almost no obvious change. Because the material was too thick, which led to higher heat and mass transfer resistance. The temperature of wet surface material was only $44.73{ }^{\circ} \mathrm{C}$ after drying for $4000 \mathrm{~s}$.

By observing the surface temperature change of $2 \mathrm{~cm}$ thick coal and $4 \mathrm{~cm}$ thick coal, the peak values were $66.19^{\circ} \mathrm{C}$ and $77.68^{\circ} \mathrm{C}$, respectively, and then the temperature decreased with the slight decrease of moisture content. However, the water content of the surface coal of $4 \mathrm{~cm}$ thickness decreased to $8 \%$ after drying $4000 \mathrm{~s}$, for the thickness of $2 \mathrm{~cm}$, only $1200 \mathrm{~s}$ is needed to reach the same surface moisture content. Moreover, it could be easily calculated that the drying rate increased about 3.3 times by decreasing the coal thickness from $4 \mathrm{~cm}$ to $2 \mathrm{~cm}$.

After drying $2 \mathrm{~cm}$ thick coal at $150{ }^{\circ} \mathrm{C}$ for $1500 \mathrm{~s}$, the water content had been reduced to $4 \%$, which completely met the final requirement.

The above data proves that the mass and heat transfer rate can be improved by reducing the thickness of the drying material in this experiment. The thickness of $2 \mathrm{~cm}$ is more suitable to be used in the new device.

\subsection{The Influence of Heat Source Temperature on the Drying Process of Thin-Layer Lane}

The drying of $2 \mathrm{~cm}$ thick coal under the heat source temperature maintained at $140{ }^{\circ} \mathrm{C}, 150{ }^{\circ} \mathrm{C}$ and $160^{\circ} \mathrm{C}$, respectively, was studied in the thin-layer plane drying experiment. Figure 6 shows the surface temperature and moisture content of the coal under $140^{\circ} \mathrm{C}, 150^{\circ} \mathrm{C}$, and $160^{\circ} \mathrm{C}$.
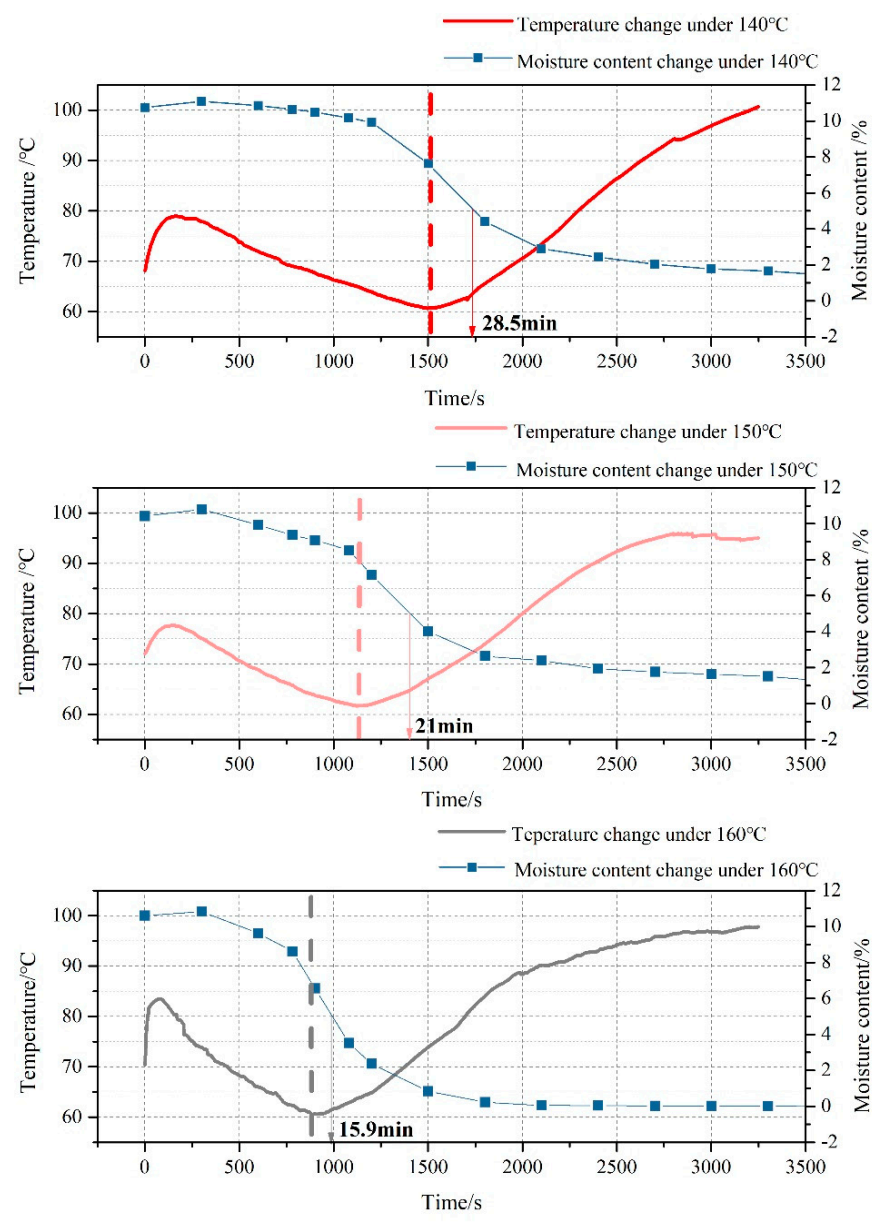

Figure 6. Surface temperature and moisture content change of $2 \mathrm{~cm}$ thick coal under different heating temperature in thin-layer drying experiment. 
Under three different heating temperatures, the surface temperature and moisture content change trends were consistent. When the heat source temperature increased, the time in which the temperature went through a rise then a decline and reached a bottom value was apparently shortened, and heat transfer was continuously accelerated. Under $160^{\circ} \mathrm{C}$, the appearance of the bottom value was $700 \mathrm{~s}$ earlier than under $140^{\circ} \mathrm{C}$. By comparing the temperature and water content change curves at different heating temperatures, it was found that every 10 degrees increase in heat source increased the heat transfer efficiency by about $25 \%$. When the heat source was $160^{\circ} \mathrm{C}$, after $15.9 \mathrm{~min}$, the overall coal moisture content was reduced to $5 \%$. In the moving bed dryer, the temperature of the heat source could be set to $160^{\circ} \mathrm{C}$, and $15.9 \mathrm{~min}$ can be set as the maximum residence time.

\subsection{Macro State Drying Characteristics of Indirect Coal Drying}

Previously, a large number of drying kinetics studies were based on direct drying [20-22]. In indirect drying, because the degree of aggregation between particles is much greater than that of direct drying, the effect of heat and mass transfer between particles cannot be ignored, it is necessary to analyze the indirectly dried coal as a whole to analyze the macro state drying characteristics.

The drying rate curve of the thin-layer drying experiment of $2 \mathrm{~cm}$ thick coal under different heat source temperature is shown in Figure 7. The abscissa in the figure is the moisture content of coal, and the ordinate is the drying rate of coal. The drying rate of coal can be calculated as:

$$
\mathrm{U}=\frac{d M}{S d t}
$$

where $\mathrm{U}$ is the drying rate, $\mathrm{kg} / \mathrm{m}^{2} \mathrm{~h} ; M$ is the amount of water expelled in the drying process, $\mathrm{kg} ; S$ is the drying area, $\mathrm{m}^{2} ; t$ is the drying time, $h$.

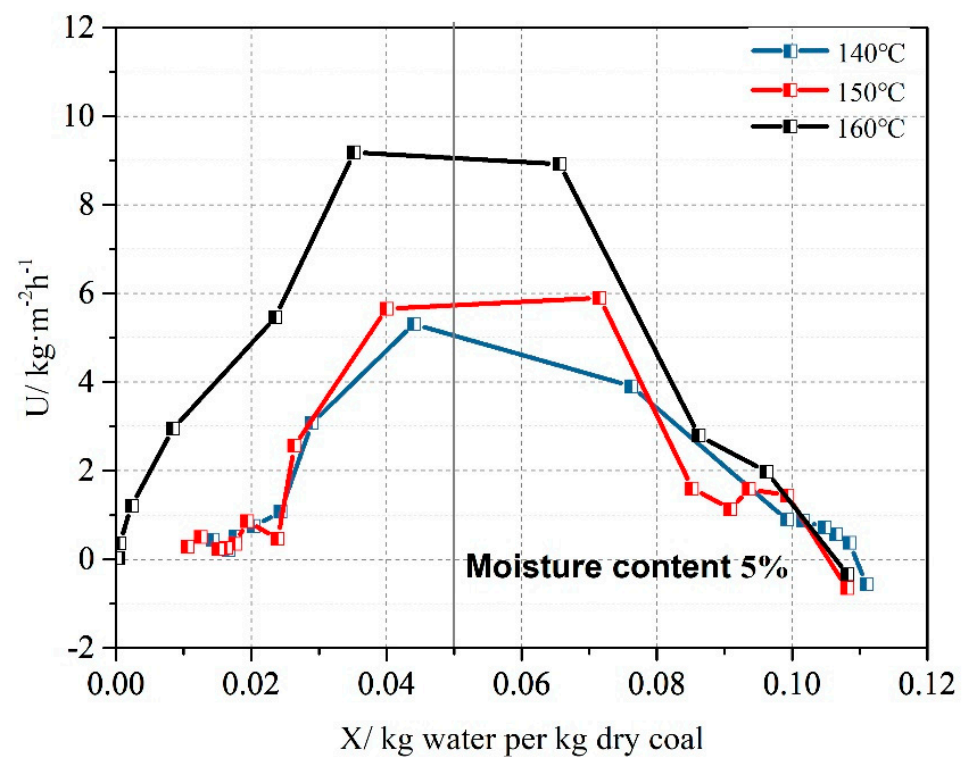

Figure 7. Drying rate of the thin-layer drying experiment of $2 \mathrm{~cm}$ thick coal.

The drying rate of the surface coal can be divided into three stages: Heat-up stage, constant-rate stage and decreased-rate stage [20,23]. At the heat-up stage, the temperature rises, but the water content is barely changed. At the constant-rate drying stage, the drying speed is completely determined by the vaporization rate, so it is also called "surface vaporization control stage". In the decreased-rate drying stage, the drying rate is determined by the diffusion rate of moisture inside the material, and it is also called the internal diffusion control stage $[18,19]$.

Compared with direct drying, the first stage of indirect drying is longer, mainly because heat needs to be transferred upward from the bottom. As is shown in Figure 7, when the moisture content 
was around $7 \%$, the surface coal entered the constant-rate drying stage. It is necessary to emphasize that the first drying stage in indirect drying cannot be called the heat-up stage like the classic drying curve, when the water content was $7 \%$, the surface temperature of the coal was around the lowest point of the temperature drop stage (in Figure 6).

At the initial stage of indirect drying, the surface temperature gradually rose, due to the heat conduction of the coal layer and the migration of the water from the inner layer to the surface layer to condense and release heat. At the same time, the temperature difference between the inner layer and outer layer resulted in the higher-pressure difference of the saturated steam [24]. At lower surface temperature, the evaporation of water content was slower, so at this stage, the surface moisture content rose slightly from $10.4 \%$ to $10.8 \%$ under $150{ }^{\circ} \mathrm{C}$. Afterwards, with increasing surface temperature, the rate of surface evaporation gradually increased, and the evaporation carried off more heat, so the surface temperature subsequently decreased by $14.6^{\circ} \mathrm{C}$ from $260 \mathrm{~s}$ to $1120 \mathrm{~s}$ under $150^{\circ} \mathrm{C}$. The drying rate increased from a negative value (The negative value of the drying rate appeared when the moisture content of the coal was higher than $10 \%$, which was in the initial stage of drying. In this stage, the drying rate was between $-1 \sim 1 \mathrm{~kg} / \mathrm{m}^{2} \mathrm{~h}$, and the value was relatively small, which indicated that there was just a fluctuation of moisture content. The surface temperature was not high enough, so the coal may absorb water from the surrounding atmosphere, which caused the increase of the moisture content) to the top value as high as $3.9,5.9$, and $9 \mathrm{~kg} / \mathrm{m}^{2} \mathrm{~h}$ under 140,150 and $160{ }^{\circ} \mathrm{C}$, respectively, heat is taken away by evaporation also increased so the temperature continued to drop. Therefore, the first stage can be named as the surface drying stage.

As the drying proceeded, the evaporation rate of the surface moisture was equal to the migration rate of moisture from the internal layer to the surface. The drying rate maintained high in this stage at around 3.9, 5.9 and $9 \mathrm{~kg} / \mathrm{m}^{2} \mathrm{~h}$ under 140,150 and $160^{\circ} \mathrm{C}$, respectively. The higher the heat source temperature, the higher the drying rate in the constant-rate drying stage. When the heat source temperature rose from $150{ }^{\circ} \mathrm{C}$ to $160^{\circ} \mathrm{C}$, the top drying rate value almost doubled.

After the moisture content of the surface layer dropped to $4 \%$, the bottom coal material was completely dry, and no inner water migrated to the surface layer. A large amount of water loss also caused the collapse of coal skeleton, and the channel of water migration was further closed. At this time, the drying rate was controlled by the migration rate of internal moisture, and it decreased with the reducing migration rate. Eventually, the moisture content of coal material was reduced to the drying limit in this air state. This stage is the decreased-rate stage.

By conducting the $2 \mathrm{~cm}$ thin-layer plane drying experiment under different temperature, it is discovered that the drying characteristics of indirect drying are highlighted in the first stage, and the key to shortening the overall drying time lies in shortening the time in the first stage, the surface drying stage. Moreover, by raising the heat source temperature, the drying rate in the constant-rate drying stage can be efficiently improved, which means that the total drying efficiency could also be improved. The heat source temperature in the newly designed device could be set as $160^{\circ} \mathrm{C}$.

\subsection{Effect of Interface Renewal on the Indirect Drying of Coal}

As is discussed above, the key to shortening the overall indirect drying time lies in shortening the time in the first drying stage-the surface drying stage. By reducing the thickness of the drying material and improving the heat source temperature, the drying rate was successfully improved. However, there was a slight increase of surface moisture content in the indirect thin-layer plane drying experiment with $8 \mathrm{~cm}, 4 \mathrm{~cm}$, and $2 \mathrm{~cm}$ thick coal in the early stage of drying. To further study the law of water migration in the indirect drying process of coal, a static side-wall indirect drying experiment was conducted.

The variation curve of moisture content and temperature, shown in Figures 8 and 9, further explained the heat and mass transfer process in porous media. As shown in Figure 8, in the static drying experiment, two trends of moisture content change are observed in progress. The moisture 
content of the coal in the inner layer and middle layer had a slight increase from $12 \%$ to about $14 \%$ then dropped constantly, but the moisture content of the coal in the outer layer showed a continuously drop.

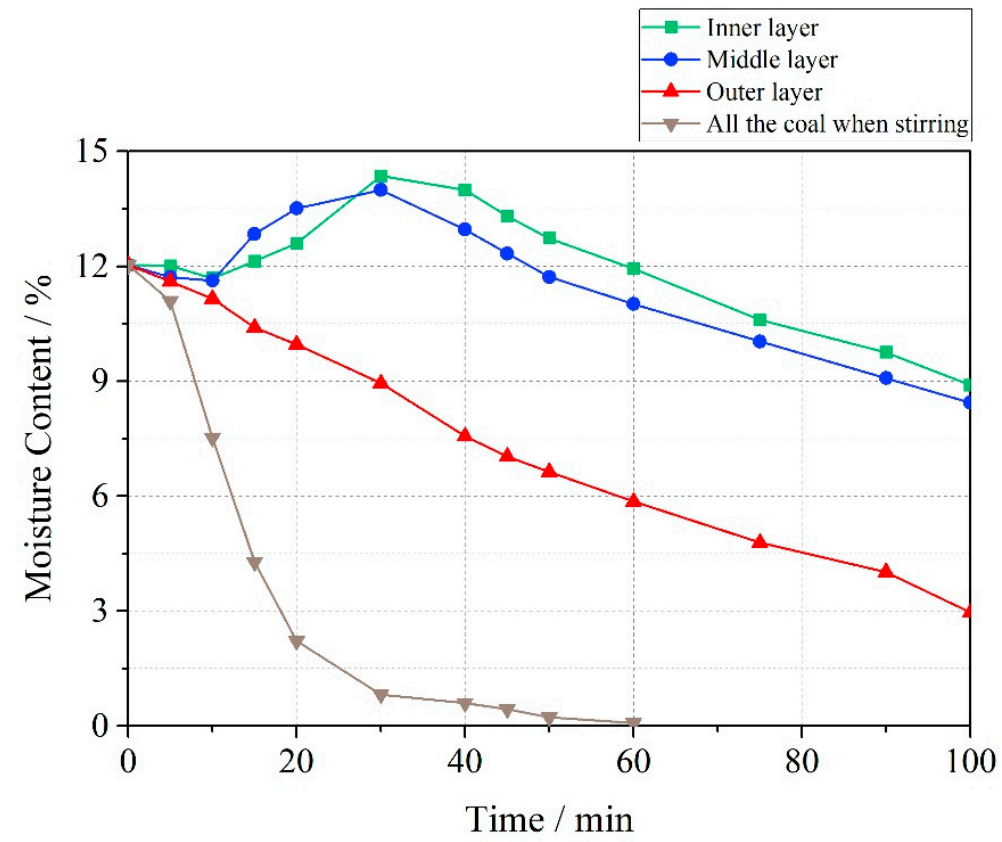

Figure 8. Moisture content change of static and stirring drying.

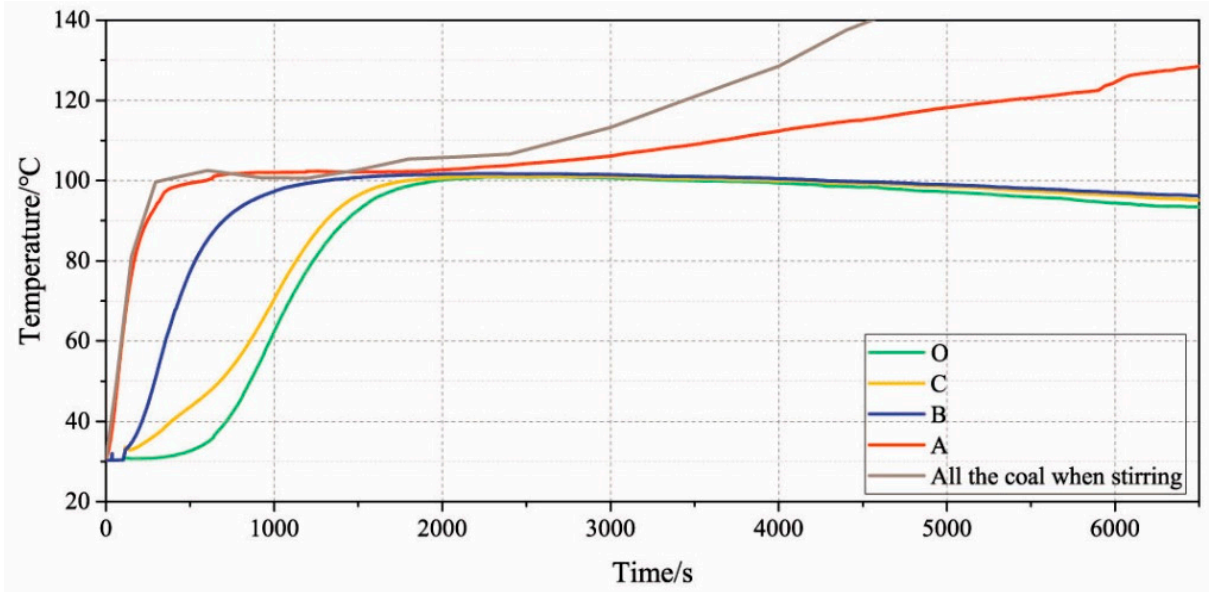

Figure 9. The temperature change of static and stirring drying.

In the static drying experiment, there was no obvious temperature difference on the circular tank sidewall. The direction of heat transfer and water content of coal was from the sidewall to the center of the circular tank. This process was divided into the following parts:

(1) The temperature difference between the circular tank sidewall and the outmost layer of the coal led to a powerful heat transfer force. Since there was no temperature difference in the longitudinal direction, the heat was gradually transferred from the sidewall to the center of the circular tank, which led to the rapid temperature growth of the outer layer of the coal. As shown in Figure 9, the closer to the heat source, the faster the coal heated up.

The average heating rate in the first $2000 \mathrm{~s}$ can be calculated as:

$$
\mathrm{R}=\frac{\Delta T}{t}
$$


where $\mathrm{R}$ is the average heating rate in $2000 \mathrm{~s},{ }^{\circ} \mathrm{C} / \mathrm{s} ; \Delta T$ is the temperature change within $2000 \mathrm{~s},{ }^{\circ} \mathrm{C}$; and $t$ is the drying time which is $2000 \mathrm{~s}$ in this calculation. The average heating rate in location $\mathrm{C}$ (out layer) was $0.2669^{\circ} \mathrm{C} / \mathrm{s}$, which is more than four times that in location $\mathrm{O}\left(0.0666^{\circ} \mathrm{C} / \mathrm{s}\right)$ within the first $2000 \mathrm{~s}$.

(2) The coal skeleton and pores in the outside area contained water as a porous medium [25], and the moisture absorbed heat and evaporated into water vapor, which diffused through the pores to the interparticle space which caused temperature difference according to the Soret Laws $[22,26]$. Since there was no temperature difference in the longitudinal direction, the water vapor generated by the bottom coal did not have the driving force to overcome the transmission resistance to the upper layer. Therefore, except for little evaporation of the upper layer, mostly water vapor could only migrate horizontally to the center of the circular tank. After entering the middle area through the pores, due to the lower coal temperature inside, the steam condensed on the middle coal to become water again $[27,28]$, and the heat released by the condensation also brought part of the heat capacity to the middle area. At this point, the water content of coal in the middle area did not decrease, but increased. As is shown in Figure 8, the moisture content of the coal in the inner layer experienced a slight increase from $12.03 \%$ to $14.36 \%$ within $30 \mathrm{~min}$ and the moisture content of the coal in the middle layer also experienced a slight increase from $12.03 \%$ to $13.99 \%$ in the same period, which indicates that there was a repeated evaporation-diffusion-condensation process causing the increasing moisture content of the coal in the certain area.

(3) As the temperature of the middle area rose, the repeated evaporation-diffusion-condensation process of transferring water and heat from the outside area to the middle area was repeated between the middle and inner area. The temperature in the inner, middle and outer layer all increased, though in different rates (Figure 9). The migration of water in the outside area was not supplemented, so it would only decline (Figure 8). Within the first $30 \mathrm{~min}$ in which the moisture content of the coal in the inner and middle layer increased, the moisture content of the coal in the outer layer decreased from $12.03 \%$ to $8.99 \%$. When the water in the outer area migrated to the middle area, the water content in the middle area had not yet moved to the inner area, and the water content in the middle area was rising. When the temperature difference between the middle area and the inner area was large enough, the water in the middle area began to migrate to the inner area, and the water content in the inner area increased. As is shown in Figure 8, within a period of $10 \mathrm{~min}$ to about $27 \mathrm{~min}$, the moisture content of the coal in the middle area was higher than that in the inner area, however, after $27 \mathrm{~min}$, the moisture content in the inner exceeded that in the middle area.

(4) The moisture in the inner area could not be further diffused horizontally, and the mass transfer resistance of the upper and lower coal layers was distinguished as a new driving force of water migration. The upper layer was in contact with dry air, so the resistance of mass transfer was low, and the resistance increased downwards from the longitudinal direction. Water could only move to the side with lower mass transfer resistance, so when the water condensed to the center, the water could only move upwards from the longitudinal direction.

In the static drying experiment, the moisture content of the coal in the outer layer reduced to $5 \%$ in about $75 \mathrm{~min}$, and the coal temperature in the outer zone was close to $120^{\circ} \mathrm{C}$ at this time. The temperature in the inner zone and the middle zone reached $100{ }^{\circ} \mathrm{C}$ at $75 \mathrm{~min}$, but the moisture content was still about $10 \%$. However, in the stirring drying experiment, because of the agitation, the bottom coal material was continuously exposed to dry air, the moisture presented in the coal particle skeleton channels did not need to migrate laterally, and even the process of longitudinal migration was broken. A large number of moisture-carrying bodies with dry air as the main body quickly took away the water. About $14 \mathrm{~min}$, the moisture content of the coal in the round tank had dropped to $5 \%$. Based on the weighting calculation of the drying rate, the total drying efficiency of stirring drying is more than seven times that of static drying. 
In porous media, the transfer of mass and heat transfer in the same direction is a slow, repetitive evaporative condensation process. Once this process is accelerated or even removed, the drying rate will increase rapidly. By turning the coal material, the contact surface of the coal material and the heat carrier is constantly updated, and the contact surface of the coal material and the moisture carrier is constantly updated which is called interface renewal. The heat and mass transfer area increases rapidly, thereby increasing the drying rate. By appropriately applying the interface renewal in the coal drying device, the drying efficiency could be effectively improved.

\subsection{The Parameter of the Moving Bed Coal Dryer}

In the stirring sidewall drying experiment, the coal at various positions on the surface was marked, and the angular velocity during mixing was measured. The average angular velocity was $0.75 \mathrm{r} / \mathrm{s}$. Choose half of the radius of the round tank to calculate the overall linear velocity, which could be calculated as:

$$
\mathrm{v}=\frac{\omega}{r}
$$

where $\mathrm{v}$ is the linear velocity, $\mathrm{m} / \mathrm{s} ; \omega$ is the angular velocity, which is $0.75 \mathrm{r} / \mathrm{s}$; and $r$ is the radius which is $0.04125 \mathrm{~m}$. The average linear velocity of coal in the stirring sidewall indirect drying experiment is $0.031 \mathrm{~m} / \mathrm{s}$.

Bring this linear velocity into the equipment design calculation, set the inclined plate width to $3.15 \mathrm{~m}$ and the coal thickness on the plate surface to $0.02 \mathrm{~m}$, the coal flow rate could be calculated as:

$$
\mathrm{W}=\mathrm{vhb \rho}
$$

where $\mathrm{W}$ is the feeding rate of coal, $\mathrm{t} / \mathrm{s}$; $\mathrm{v}$ is the linear velocity, which is $0.031 \mathrm{~m} / \mathrm{s} ; h$ is the coal thickness on the inclined plate, which is $0.02 \mathrm{~m}$; $b$ is the width of the plate, which is $3.15 \mathrm{~m}$; and $\rho$ is the bulk density of coal, which is $0.7 \mathrm{t} / \mathrm{m}^{3}$. The calculated coal feeding rate is $4.9 \mathrm{t} / \mathrm{h}$.

The coal feeding rate of this device is set to $4.9 \mathrm{t} / \mathrm{h}$. Drying conditions should be determined primarily considering the drying efficiency and effects on the quality of the product [29]. According to the experimental data of the thin-layer plane drying experiment, the heat source temperature is set to $160{ }^{\circ} \mathrm{C}$ and the total residence time of the coal in the device is set to $15 \mathrm{~min}$, or $900 \mathrm{~s}$. Other parameters are calculated and shown in Table 3.

Table 3. Parameters of the moving bed coal dryer.

\begin{tabular}{cccc}
\hline Parameters & Value & Parameters & Value \\
\hline Steam flow rate & $300 \mathrm{~m}^{3} / \mathrm{h}$ & Coal feeding rate & $4.9 \mathrm{t} / \mathrm{h}$ \\
\hline Total height & $19.7 \mathrm{~m}$ & Gas outlet diameter & $10 \mathrm{~cm}$ \\
\hline Width & $3.15 \mathrm{~m}$ & Inclined plate length & $4 \mathrm{~m}$ \\
\hline Coal descending port width & $8 \mathrm{~cm}$ & Inclined plate number & 7 \\
\hline Coal deflector length & $5 \mathrm{~cm}$ & Inclined plate slope & $40^{\circ}$ \\
\hline
\end{tabular}

The mesh model obtained is shown in Figure 10, quad structured mesh with a total number of 311,649 meshes (The amount of mesh is determined according to the convergence time and degree.) 


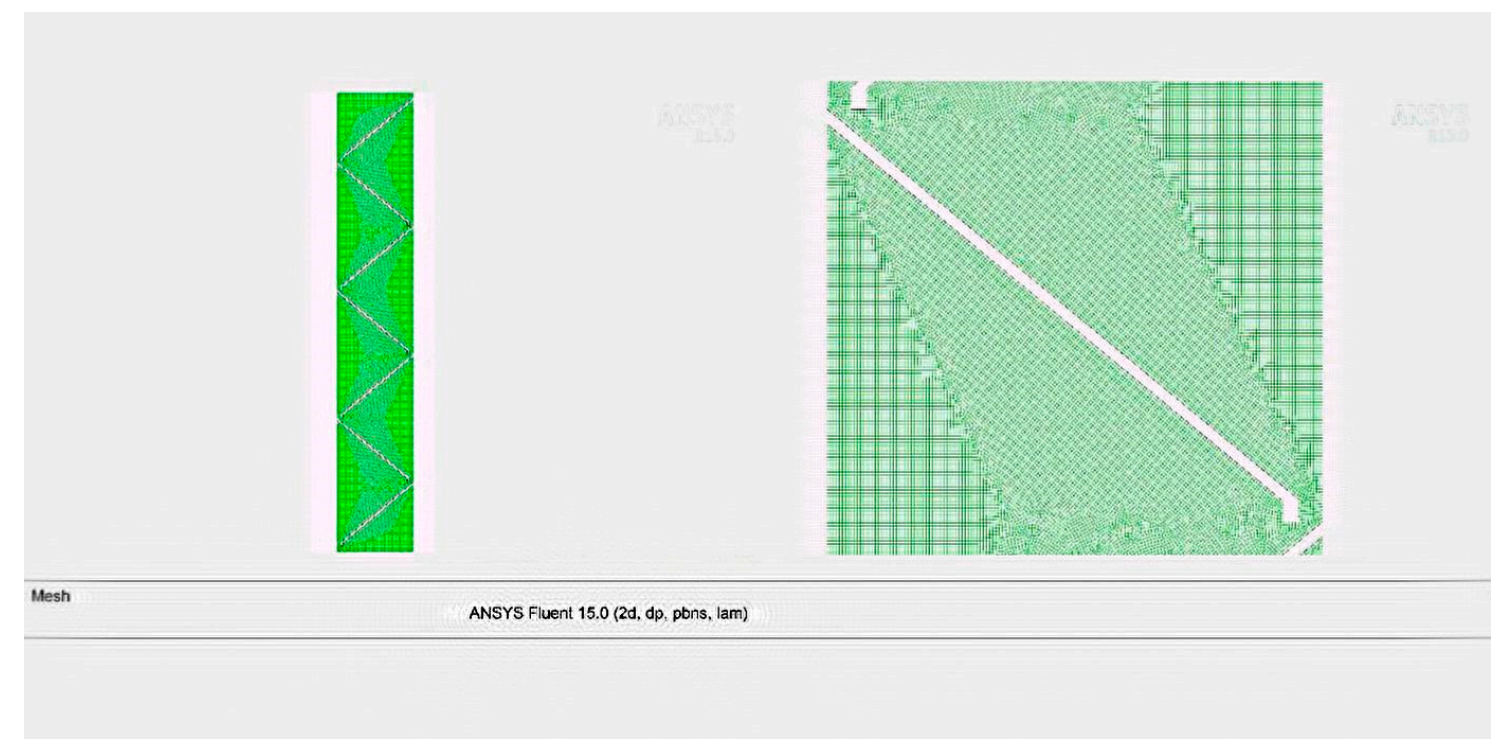

Figure 10. Mesh model diagram of the new moving bed coal moisture control device and partial enlarging detail (2d: two dimensions).

\subsection{Simulation of the Moving Bed Coal Dryer}

The seven inclined plates were marked as Plate A to Plate G from top to bottom. Set the temperature of the plates' surface temperature at $160^{\circ} \mathrm{C}$ (the plates heat evenly), set the space above Plate A as non-sealed, so the temperature above Plate A is almost the ambient temperature. The internal temperature cloud of the device is shown in Figures 11 and 12.

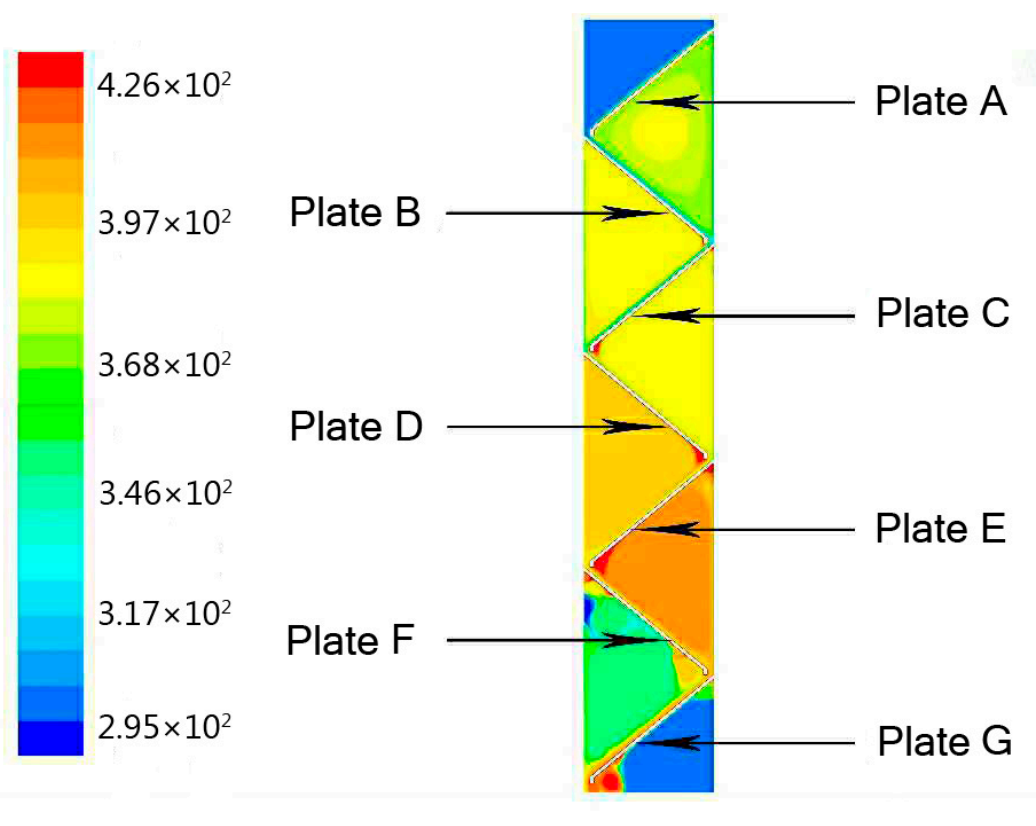

Contours of Static Temperature (K)

ANSYS Fluent $15.0(2 \mathrm{~d}, \mathrm{dp}, \mathrm{pbns}$, lam)

Figure 11. Internal temperature cloud of the new moving bed coal moisture control device. 

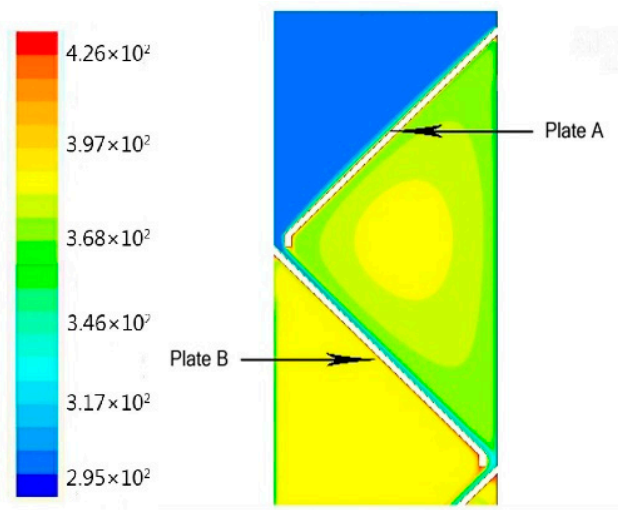

( a )

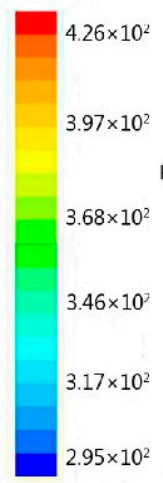

$2.95 \times 10^{2}$

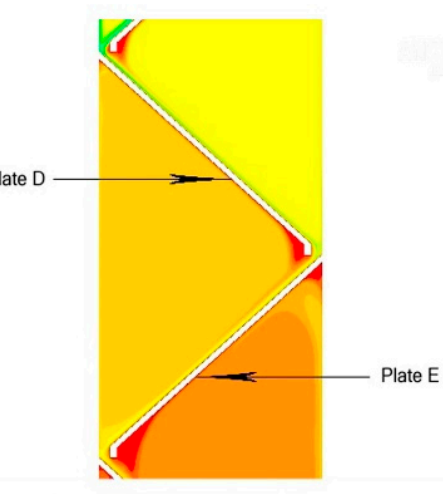

(c)
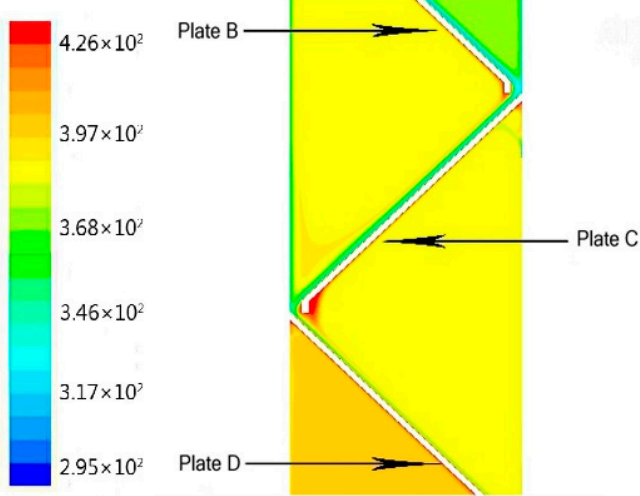

( b )

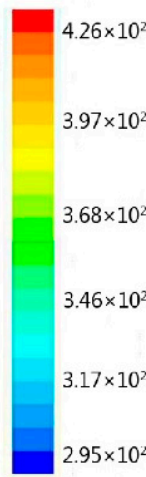

$2.95 \times 10^{2}$

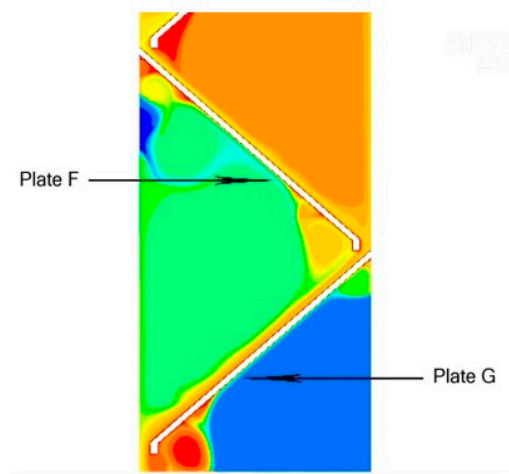

(d)

\section{Contours of Static Temperature (K)}

ANSYS Fluent $15.0(2 \mathrm{~d}, \mathrm{dp}$, pbns, lam)

Figure 12. Partial enlarging internal temperature cloud of the new moving bed coal moisture control device: (a) internal temperature cloud from Plate A to Plate B; (b) internal temperature cloud from Plate B to Plate D; (c) internal temperature cloud from Plate D to Plate E; (d) internal temperature cloud from Plate F to Plate G.

Coal enters the device evenly from the uppermost coal inlet with a mass flow rate of $4.9 \mathrm{t} / \mathrm{h}$. From the overall view, as shown in Figure 11, the temperature of the space near the coal inlet and bottom outlet is lower, and the temperature of the middle space is higher.

Firstly, the coal material accumulates on Plate A to form the uppermost blue low-temperature zone, which is next to the pulverized coal layer on Plate A. The temperature starts to rise, and the temperature can reach $60^{\circ} \mathrm{C}$. At the coal descending port of Plate A, the coal fell to Plate B, forming a $2 \mathrm{~cm}$ thick coal seam on Plate B, and falling at an average speed of $0.0317 \mathrm{~m} / \mathrm{s}$.

It should be noted that the coal in the lower layer which is the closest to the heat source heated to $60{ }^{\circ} \mathrm{C}$ on Plate A becomes the upper layer on Plate B, due to the overturn at the descending port. When reaching the bottom of Plate $\mathrm{B}$, the temperature of the lower layer surpasses the temperature of the upper layer and reaches $80^{\circ} \mathrm{C}$. The effect of the interface renewal is reflected in this process.

The specific status of the interface renewal of the coal descending port of each plate is further described in detail by the flow velocity field. In Figure 13, the velocity field and temperature field of the descending port from Plate $B$ to Plate $C$ is shown. 


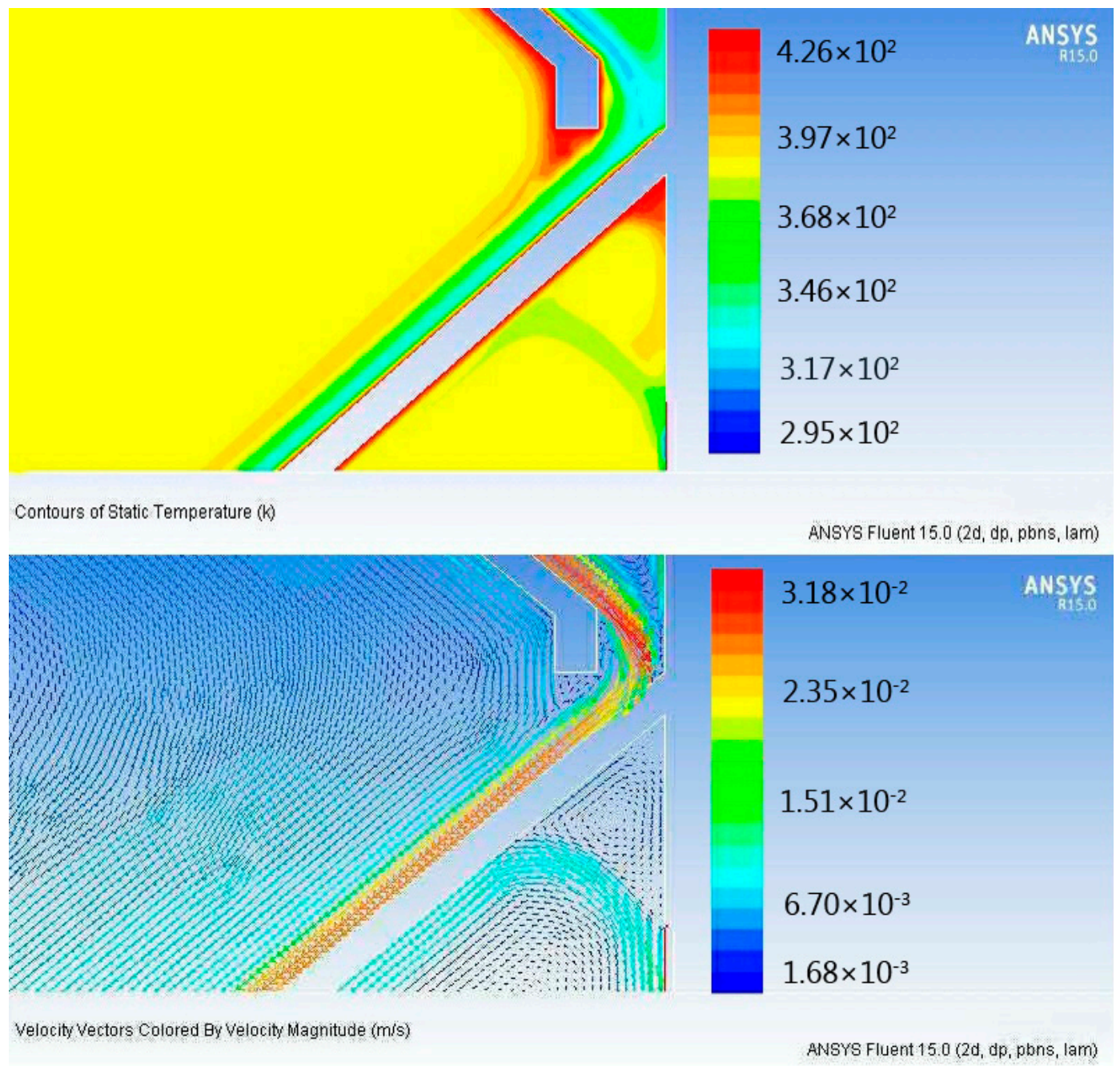

Figure 13. The velocity field and temperature field of the descending port from Plate B to Plate C.

As shown in Figure 13, taking the coal material descending port from Plate B to Plate $\mathrm{C}$ as an example, the direction indicated by the arrow is the flow direction of the main fluid coal material, and the speed is distinguished by color.

It can be seen from the velocity field that the coal material movement at the descending port is not turbulent or disordered. Due to the difference in thickness, the upper coal layer of the upper inclined plate will be closer to the outer wall of the device than the lower coal material: During the descending process, the upper coal layer first hits the outer wall of the device and falls to the next inclined plate along the outer wall. Moreover, after losing the supporting force of the previously declined plate, the lower coal layer directly falls on the original upper coal layer that has covered the next declined plate. At this time, the upper and lower coal layer are replaced, and the interface renewal process completes.

Comparing the velocity field and temperature field in the same area can further verify the manifestation of the interface renewal. As shown in Figure 13, the lower coal layer of plate B of which the temperature is close to $80^{\circ} \mathrm{C}$ becomes the upper coal layer on Plate $\mathrm{C}$, and the upper coal layer of Plate $\mathrm{B}$ at the temperature of $60^{\circ} \mathrm{C}$ is transferred to the lower layer on plate $\mathrm{C}$ through the interface renewal, thereby forming three different temperature zones on Plate $\mathrm{C}$ from top to bottom. The low-temperature zone is the closest to the heat source, due to the interface renewal effect. At the same time, the temperature difference between the heat source and the low-temperature zone is the largest, so that the driving force of heat transfer is large, and the overall heating rate is accelerated.

The following Figure 14 shows the temperature distribution of the coal outlet section. 


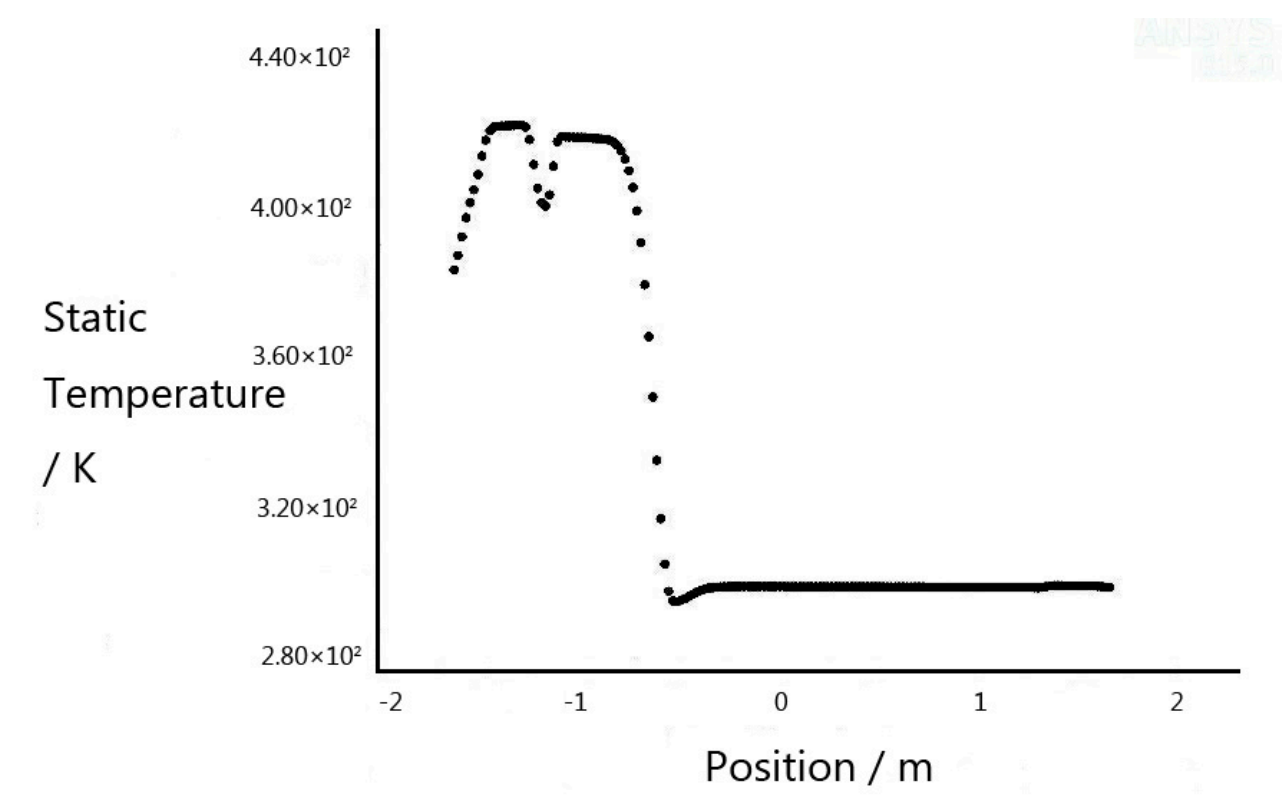

Static Temperature

ANSYS Fluent 15.0 (2d, dp, pbns, lam)

Figure 14. The temperature distribution of the dry coal outlet section.

As shown in Figure 14, the coal material continues to descend after leaving Plate B. When it reaches the bottom of Plate $\mathrm{C}$, the total residence time of the coal in the device is about $380 \mathrm{~s}$, and the temperature reaches $90^{\circ} \mathrm{C}$; when it reaches the bottom of Plate $\mathrm{D}$, the total residence time is about $500 \mathrm{~s}$, and the temperature reaches above $100{ }^{\circ} \mathrm{C}$. According to the law of temperature rise in the thin-layer plane drying experiment, the water content in the coal feed has dropped below $6 \%$. The heat transfer process then tends to be dominated by the thermal conductivity of pure coal, and the temperature of the coal feed continues to rise at a constant rate. Since the space between Plate F and Plate G is close to the coal outlet temperature, when the coal reaches Plate $G$, its temperature is already much higher than the space temperature, and the temperature of the coal from the bottom of Plate $G$ is close to the heat source temperature. The curve shown in Figure 14 is the temperature distribution of the dry coal outlet section. The horizontal axis shows the horizontal coordinate of the dried coal outlet. After the coal material drops from the lower outlet of Plate $G$ and leaves from the coal outlet, the temperature on the left side of the curve has reached $420 \mathrm{~K}$, which is equivalent to $146-147^{\circ} \mathrm{C}$. It means that if there is an interface renewal, the heat transfer rate of the coal material in the residence time of $900 \mathrm{~s}$ is significantly improved.

According to the simulation results, the number of inclined plates can be further reduced from seven to four without changing the length of the plate, or the length of the plate can be reduced without changing the number of plates.

By changing the number of the inclined plate or the length of the plate, the total residence time of coal in the device can be changed. By controlling the total residence time of coal, coal with certain moisture content could be obtained, so that this new moving bed dryer could be applied in the CMC technology.

\subsection{Benefit Assessment of the Moving Bed Coal Dryer}

According to the experimental results and the operating parameters of the equipment, the benefits of the moving bed dryer and the two existing CMC systems are evaluated, as shown in Table 4. 
Table 4. Benefit assessment of STD (Steam Tube Dryer), fluidized bed and moving bed dryer [30,31].

\begin{tabular}{cccc}
\hline Parameters & STD & Fluidized Bed Dryer & Moving Bed Dryer \\
\hline Coal feeding rate $/ \mathrm{t} \cdot \mathrm{h}^{-1}$ & 330 & 186 & 4.9 \\
Initial coal moisture content $/ \%$ & 9.8 & 10.2 & 12 \\
Final coal moisture content $\%$ & 6.8 & 6.5 & 6 \\
Moisture carrier flow $/ \mathrm{Nm}^{3} \cdot \mathrm{t}^{-1}(\mathrm{dry}$ coal $)$ & 103.6 & 1290 & 70.09 \\
\hline
\end{tabular}

From the comparison in Table 4, it can be seen that compared to the traditional two CMC processes, the moving bed has certain advantages in energy saving, since it requires less moisture carrier than the other two traditional technology.

\section{Conclusions}

Based on pollution control, a new indirect heat transfer technology for coal moisture control is proposed in this paper, in order to improve drying efficiency and reduce energy consumption of indirect heating. Through the experiment, the basic research of this new type of coal moisture control technology was carried out, and simulation software was used to prove its efficiency.

Through the sidewall heat transfer experiment, it was found that the repeated phase change process leads to a low drying rate. In order to reduce the mass transfer resistance, the coal material is stirred at a constant speed, so that the contact surface of the coking coal and the heat source is constantly updated, and the contact surface between the coal material and the wetted body is also constantly updated. It was found that the drying rate was more than seven times of the static state. It was proved that the interface renewal was an effective way to enhance the indirect heat and mass transfer rate. At the same time, through thin layer plane heat transfer experiment, it is found that thin layer drying has a positive effect on indirect heat and mass transfer rate. Therefore, a new type of device design is proposed. The hollow inclined plate with hot steam is used as the heat source, and the coal particles form thin layer flow on the multi-layer inclined plate with their own gravitational potential energy, which can reduce the energy consumption of the interface renewal while maintaining the interface update effect. The moisture content is controlled by the number of inclined plates and the residence time of the coal in the device. Based on the experimental data of heat transfer in the thin-layer plane drying experiment, the device was preliminarily determined to be dried at $160^{\circ} \mathrm{C}$ with a thickness of $2 \mathrm{~cm}$, and the moisture content was reduced from $12 \%$ to $5 \%$ in $15.9 \mathrm{~min}$. Fluent software is used to model and simulate the running process. The results show that the interface update can increase the heat transfer rate twice, and the number of inclined plates can be reduced from seven to four in the pilot plant.

Based on the investigation of the indirect heat and mass transfer characteristics of coal, the new type of moving bed coal moisture control device and its technical parameters are put forward, which has certain reference value for further promoting energy saving in coking industry.

Author Contributions: Conceptualization, M.Y. and X.S.; methodology, M.Y. and X.S.; software, M.Y.; validation, M.Y., X.S. and J.T.; formal analysis, M.Y.; investigation, M.Y.; resources, S.Z.; data curation, M.Y. and X.S.; writing-original draft preparation, M.Y. and X.S.; writing—review and editing, M.Y., J.T., X.L., X.Y. and Z.Z.; visualization, M.Y.; supervision, S.Z. and X.L.; project administration, S.Z. All authors have read and agreed to the published version of the manuscript.

Funding: This research received no external funding.

Conflicts of Interest: The authors declare no conflict of interest. 


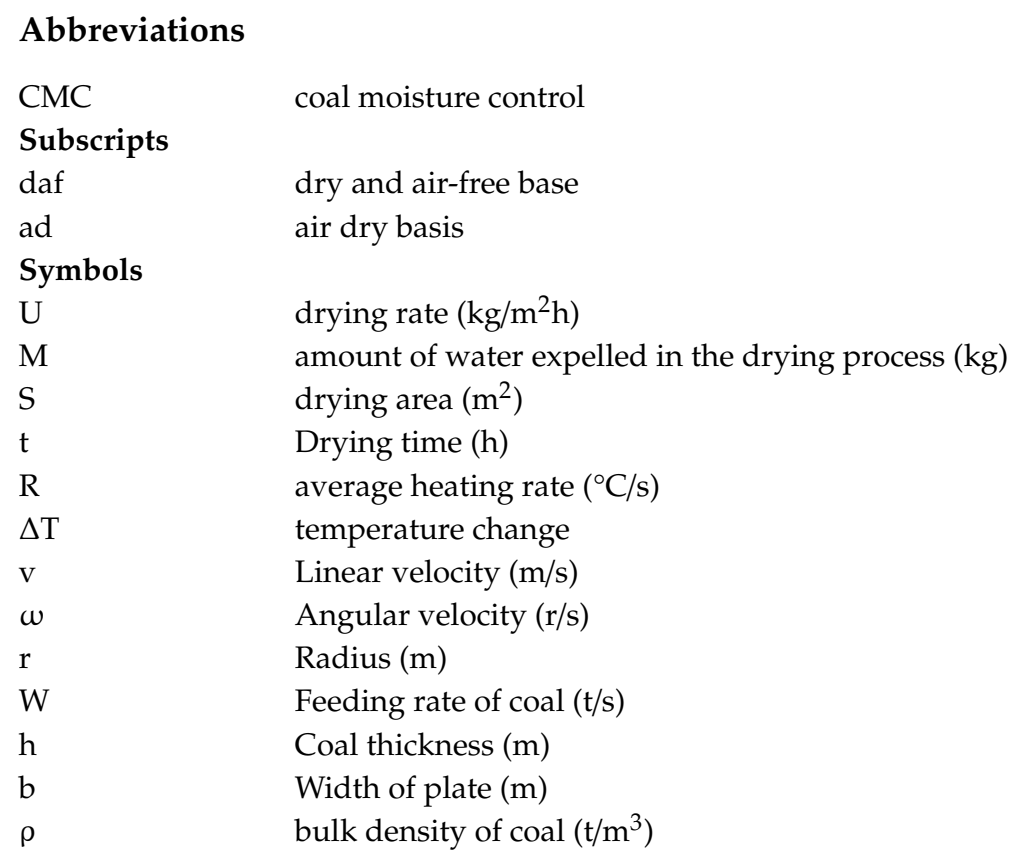

\section{References}

1. Gong, M.-H.; Yi, Q.; Huang, Y.; Wu, G.-S.; Hao, Y.-H.; Feng, J.; Li, W. Coke oven gas to methanol process integrated with $\mathrm{CO} 2$ recycle for high energy efficiency, economic benefits and low emissions. Energy Convers. Manag. 2017, 133, 318-331. [CrossRef]

2. Lin, B.; $\mathrm{Wu}, \mathrm{R}$. Designing energy policy based on dynamic change in energy and carbon dioxide emission performance of China's iron and steel industry. J. Clean. Prod. 2020, 256, 120412. [CrossRef]

3. Seo, M.W.; Jeong, H.M.; Lee, W.J.; Yoon, S.J.; Ra, H.W.; Kim, Y.K.; Lee, D.Y.; Han, S.W.; Kim, S.D.; Lee, J.-G.; et al. Carbonization characteristics of biomass/coking coal blends for the application of bio-coke. Chem. Eng. J. 2020, 394, 124943. [CrossRef]

4. Plutecki, Z.; Sattler, P.; Ryszczyk, K.; Duczkowska, A.; Anweiler, S. Thermokinetics of Brown Coal during a Fluidized Drying Process. Energies 2020, 13, 684. [CrossRef]

5. Chen, H.; Qi, Z.; Chen, Q.; Wu, Y.; Xu, G.; Yang, Y. Modified high back-pressure heating system integrated with raw coal pre-drying in combined heat and power unit. Energies 2018, 11, 2487. [CrossRef]

6. Zhang, J.; Wu, R.; Zhang, G.; Yu, J.; Yao, C.; Wang, Y.; Gao, S.; Xu, G. Technical review on thermochemical conversion based on decoupling for solid carbonaceous fuels. Energy Fuels 2013, 27, 1951-1966. [CrossRef]

7. Pal, P.; Kumar, R. Treatment of coke wastewater: A critical review for developing sustainable management strategies. Sep. Purif. Rev. 2013, 43, 89-123. [CrossRef]

8. Kato, K.; Nomura, S. Coal pre-treating technologies for improving coke quality. In Proceedings of the International Congress on the Science and Technology of Iron Making, Shanghai, China, 20 October 2009; pp. 361-366.

9. Nomura, S.; Arima, T.; Kato, K. Coal blending theory for dry coal charging process. Fuel 2004, 83, 1771-1776. [CrossRef]

10. Liu, Z.; Xie, Y.; Wang, Y.; Yu, J.; Gao, S.; Xu, G. Tandem fluidized bed elutriator-Pneumatic classification of coal particles in a fluidized conveyer. Particuology 2012, 10, 600-606. [CrossRef]

11. Nakagawa, T.; Kato, K.; Naito, M. Carbon deposition mechanism in coke oven chamber-influence of fine particles on formation rate of carbon deposit. Nippon Steel Technol. Rep. 2006, 94, 63-68.

12. Mu, L.; Peng, L.; Liu, X.; Bai, H.; Song, C.; Wang, Y.; Li, Z. Emission characteristics of heavy metals and their behavior during coking processes. Environ. Sci. Technol. 2012, 46, 6425-6430. [CrossRef] [PubMed]

13. Zhang, K.; You, C. Numerical simulation of lignite drying in a packed moving bed dryer. Fuel Process. Technol. 2013, 110, 122-132. [CrossRef]

14. Bruce, D.; Giner, S. Mathematical modelling of grain drying in counter-flow beds: Investigation of crossover of air and grain temperatures. J. Agric. Eng. Res. 1993, 55, 143-161. [CrossRef] 
15. Barrozo, M.A.S.; Sartori, D.J.M.; Freire, J.T. Quality analysis of soybean seeds dried in a cross flow moving bed. Seed Sci. Technol. 2000, 28, 169-177.

16. Lira, T.; Barrozo, M.A.S.; Assis, A. Concurrent moving bed dryer modelling: Sensitivity of physicochemical parameters and influence of air velocity profiles. Appl. Therm. Eng. 2009, 29, 892-897. [CrossRef]

17. Lacerda, A.F.; Lisboa, M.H.; Barrozo, M.A. Heat and mass transfer in a countercurrent moving bed dryer. Appl. Therm. Eng. 2005, 25, 2641-2652. [CrossRef]

18. Vorres, K.S. Effect of temperature, sample size, and gas flow rate on drying on beulah-zap lignite and wyodak subbituminous coal. Energy Fuels 1994, 8, 320-323. [CrossRef]

19. Vorres, K.S.; Wertz, D.L.; Malhotra, V.; Dang, Y.; Joseph, J.; Fisher, R. Drying of beulah-zap lignite. Fuel 1992, 71, 1047-1053. [CrossRef]

20. Zhao, H.; Li, Y.; Song, Q.; Wang, X.; Shu, X. Drying, re-adsorption characteristics, and combustion kinetics of Xilingol lignite in different atmospheres. Fuel 2017, 210, 592-604. [CrossRef]

21. Li, X.; Song, H.; Wang, Q.; Meesri, C.; Wall, T.; Yu, J. Experimental study on drying and moisture re-adsorption kinetics of an Indonesian low rank coal. J. Environ. Sci. 2009, 21, S127-S130. [CrossRef]

22. Meshalkin, V.; Bobkov, V.; Dli, M.; Dovì, V. Optimization of energy and resource efficiency in a multistage drying process of phosphate pellets. Energies 2019, 12, 3376. [CrossRef]

23. Wang, Y.; Wang, Y.-Y.; Zhang, S. Effect of drying conditions on moisture re-adsorption and particulate matter emissions during the classification drying of coking coal. Fuel Process. Technol. 2019, 192, 65-74. [CrossRef]

24. Pakowski, Z.; Adamski, R.; Kokocińska, M.; Kwapisz, S. Generalized desorption equilibrium equation of lignite in a wide temperature and moisture content range. Fuel 2011, 90, 3330-3335. [CrossRef]

25. Ahamed, M.A.A.; Perera, M.S.A.; Matthai, S.K.; Ranjith, P.G.; Dong-yin, L. Coal composition and structural variation with rank and its influence on the coal-moisture interactions under coal seam temperature conditions-A review article. J. Pet. Sci. Eng. 2019, 180, 901-917. [CrossRef]

26. Somers, E. Theoretical considerations of combined thermal and mass transfer from a vertical flat plate. J. Appl. Mech. 1956, 23, 295-301.

27. Komatsu, Y.; Sciazko, A.; Zakrzewski, M.; Kimijima, S.; Hashimoto, A.; Kaneko, S.; Szmyd, J.S. An experimental investigation on the drying kinetics of a single coarse particle of Belchatow lignite in an atmospheric superheated steam condition. Fuel Process. Technol. 2015, 131, 356-369. [CrossRef]

28. Zakrzewski, M.; Sciazko, A.; Komatsu, Y.; Akiyama, T.; Hashimoto, A.; Kaneko, S.; Kimijima, S.; Szmyd, J.S.; Kobayashi, Y. Numerical analysis of single and multiple particles of Belchatow lignite dried in superheated steam. Heat Mass Transf. 2018, 54, 2215-2230. [CrossRef]

29. Araújo, M.D.V.; Correia, B.B.; Brandão, V.A.A.; De Oliveira, I.R.; Santos, R.S.; Neto, G.L.D.O.; Silva, L.P.D.L.; De Lima, A.G.B. Convective drying of ceramic bricks by CFD: Transport phenomena and process parameters analysis. Energies 2020, 13, 2073. [CrossRef]

30. Yang, D.; Jin, J.; Yu, H.; Li, R. The energy efficiency analysis of CMC by cascade sieving and fluidized bed with immersed tubes (EN-CMC). In Proceedings of the Coking Energy Conservation, Environmental Protection and CDQ Technology Symposium, Dalian, China, 13 September 2018; pp. 150-157.

31. Yang, J.; Zhang, Z. Energy efficiency analysis on coal moisture control. Fuel Chem. Eng. 2014, 45, 1-3.

(C) 2020 by the authors. Licensee MDPI, Basel, Switzerland. This article is an open access article distributed under the terms and conditions of the Creative Commons Attribution (CC BY) license (http://creativecommons.org/licenses/by/4.0/). 